\title{
Extended Simulated Distillation by Capillary Supercritical Fluid Chromatography
}

\author{
A. Dulaurent ${ }^{2}$, L. Dahan ${ }^{2}$, D. Thiébaut ${ }^{2}$, F. Bertoncini ${ }^{1}$ and D. Espinat ${ }^{1}$ \\ 1 Institut français du pétrole, IFP-Lyon, Département Caractérisation des produits, BP 3, 69390 Vernaison - France \\ 2 Laboratoire Environnement et chimie analytique, École supérieure de chimie et de physique industrielle, 10 rue Vauquelin, 75005 Paris - France \\ e-mail: fabrice.bertoncini@iff.fr - didier.thiébauや@espci.fr - didier.espinał@ifp.fr
}

\begin{abstract}
Résumé - Distillation simulée étendue par chromatographie en phase supercritique - La distillation simulée (simdist) fondée sur une séparation par chromatographie en phase gazeuse (CPG) est largement répandue dans l'industrie pétrolière afin d'évaluer les huiles comme les charges et recettes des procédés de raffinage et de conversion du pétrole brut. Grâce à une courbe de calibration reliant le temps de rétention à la température d'ébullition de paraffines normales, la distillation simulée fournit la distribution des hydrocarbures d'un échantillon (en \% poids) en fonction du point d'ébullition de cette fraction. Les conditions expérimentales de la distillation simulée sont ajustées pour obtenir des résultats en accord avec les méthodes de distillation physiques qui fournissent la température d'ébullition vraie. Cependant, cette technique n'est pas compatible avec les fractions lourdes (point final supérieur à $700^{\circ} \mathrm{C}$ ) en raison de la limitation de la volatilité et du manque de résistance des composés de haut poids moléculaire envers les réactions de craquage. L'intérêt de la chromatographie en phase supercritique (CPS) réside dans le fait que les hautes températures ne sont pas requises et que le mécanisme pour étendre la limite supérieure de la courbe de distillation dépend de la solubilité de l'échantillon dans la phase supercritique. Cet article présente des avancées récentes en distillation simulée basée sur la CPS. Comparativement à la CPG, la CPS étend la gamme de cette application jusqu'au $\mathrm{nC}_{126}$ et rend possible une extrapolation jusqu'au $\mathrm{nC}_{200}$. Par conséquent, la CPS est un outil de choix pour obtenir une meilleure quantification de la conversion des fractions pétrolières lourdes.
\end{abstract}

\footnotetext{
Abstract - Extended Simulated Distillation by Capillary Supercritical Fluid Chromatography Simulated distillation (simdist) based on separation using gas chromatography $(G C)$ is widely spread in the petroleum industry for evaluation of fossil fuels as well as petroleum feeds and cuts produced by refining and conversion processes. Through a calibration curve relating the boiling point of normal paraffins to their elution temperature or retention time, simdist provides the hydrocarbon distribution of the sample (in weight percent) versus the boiling range of the fraction. The operating conditions used for simdist are tuned to be in agreement with preparative distillation that gives the True Boiling Point (TBP) curve. However, this technique is not compatible to heavy ends (FBP higher than $700^{\circ} \mathrm{C}$ ) due to the limitation of volatility of the products and the lack of resistance of high molecular-weight hydrocarbons to cracking reactions. The interest of supercritical-fluid chromatography (SFC) is that high temperatures are not needed to elute heavy ends and that the mechanism for extending the upper limit of simdist depends only on sample solubility into the supercritical mobile phase. This paper presents recent advances in Simdist using SFC of heavy fractions. Compared to GC, SFC extends the range of this application up to $n C_{126}$ hydrocarbons and makes possible to calibrate up to $n C_{200}$. Thus, SFC could be the tool of choice for better determination of conversion in heavy petroleum-fraction processing.
} 


\section{INTRODUCTION}

In the field of petroleum industry, distillation is the most widely used technique for determining the boiling range of petroleum products. Distillation data are required for the characterization of feedstocks and products and for process monitoring in the refinery. Various standard methods have been developed by the American Society for Testing and Materials (ASTM): a true boiling point (TBP) profile for crude oils is provided by ASTM D2892 standard method whereas a simpler standard method, ASTM D86, can be carried out for a single-plate distillation of middle distillates. Another standard method, ASTM D1160, is operated to perform vacuum distillation for the characterization of heavy ends. Even if these methods are well known and robust, they suffer from several drawbacks: they appear as time consuming (several days are necessary for a TBP distillation), not automatic, and they require large samples.

In the early 60's, some authors [1] proposed to use the chromatographic profile from gas chromatography separation in order to replicate the TBP distillation. This concept of simulated distillation (simdist) is based on the fact that, using an apolar column and a temperature program, the components of the sample are eluted according their increasing boiling point. A mixture of standard compounds whose boiling point is well known such as normal paraffins is used for establishing a relationship between retention times and boiling points. Through this calibration curve, simdist gives the hydrocarbon distribution of the sample (expressed in weight percent) versus the boiling range of the fraction (expressed in Atmospheric Equivalent Boiling Point or AEBP). The conditions used for simdist, the choice of both the column and the experimental conditions [2-5] are tuned to provide results in agreement with preparative distillation that gives the TBP curve (as described in ASTM D2892). The first methods were originally developed for gasoline (ASTM D3710 [6]). Several other methods have been standardized (ASTM D2887 and D5307 [7-8]) for middle distillates with a final boiling point (FBP) up to $538^{\circ} \mathrm{C}$ (corresponding to $\mathrm{nC}_{44}$ ).

Nevertheless, these methods were not able to deal with non-eluting residue, whose quantity could be measured by internal standard. Much effort has gone into extending the range of eluted compounds up to an FBP of $700^{\circ} \mathrm{C}$. In the 80 's, the Institut français du pétrole (IFP) [9] developed a method for samples containing non-distillable fractions by using a pre-column with a backflush to eliminate the heavy fractions from the analytical column. Simdist was allowed up to $575^{\circ} \mathrm{C}$ using an internal standard for the quantification of the heavy fraction. In the 90 's, new analytical approaches have been implemented to deal with the heavy ends: wide bore capillary columns have been introduced [10] and new thermally-stable capillary columns $[4,11]$ with aluminum or stainless steel coating for performing high-temperature GC (HTGC). Normal paraffin with 100 carbons was eluted using a final oven temperature of $430^{\circ} \mathrm{C}$ [10]. Unfortunately, large bleeding of the stationary phase at high temperatures was responsible of baseline drift and variation of retention times. Besides, at oven temperatures up to $430^{\circ} \mathrm{C}$, the resistance of high molecular-weight hydrocarbons to cracking reactions is questionable [11].

To overcome these limitations, supercritical-fluid chromatography (SFC) has been investigated to carry out high temperature simulated distillation. Since the beginning of the 80 's, SFC has become a tool of choice for the separation of petroleum compounds, especially for heavy petroleum-fraction.

Indeed, the solvating properties of supercritical fluids like carbon dioxide, similar to non polar organic solvents, and the kinetics abilities of supercritical fluids allow important advantages to SFC. The diffusion of solutes in supercritical fluids is greater than that in liquids (and about three times less than in gases) resulting in a decrease in resistance to mass transfer in the column and allows for fast high resolution separations [12-13]. The solvent strength of a supercritical fluid at constant temperature is approximately proportional to its density, which can be controlled by carefully choosing the pressure conditions. So the solvating power of a supercritical fluid can be increased during an analysis using positive pressure or negative temperature gradients at constant temperature or pressure respectively. Many experiments are performed by programming the pressure at constant temperature causing a large change in density [12-13] to permit the elution of high molecular weight compounds at temperatures where the risk of thermal degradation of analytes and stationary phases is low. SFC also offers the capability to use many type of detectors including a non-selective gas-phase detector such as the flame ionization detector (FID) for which response factors of hydrocarbons show no significant differences versus their structure except when they contain heteroelements.

Thus SFC can provide fast high-resolution chromatography at much lower temperatures than GC and is a very attractive technique for eluting hydrocarbons having more than 80 carbons, which are difficult to elute in GC or HTGC.

Until now, the results published on simdist of heavy products by SFC depend strongly on the experimental conditions: column type, temperature, pressure gradient, injection system [12-16]. Both capillary GC-like columns and LC packed-columns were used, non-polar stationary-phases being preferred in order to ensure elution according to the boiling points of the analytes, while maintaining very low aliphatic-aromatic selectivity. The density of the mobile phase is increased during the separation via pressure programming at constant column temperatures between $100-180^{\circ} \mathrm{C}$. Very high pressures (up to $500 \mathrm{bar}$ ) are required for eluting heavy components exceeding $\mathrm{nC}_{100}$. Injections are also performed at temperatures higher than $100^{\circ} \mathrm{C}$, mainly for dissolving the standards used for correlating retention times and boiling points. 
The best results using packed columns were obtained by Sotty et al. [14] and Huynh et al. [15]. Sotty et al. used a column packed with undecyl-bonded silica $\left(\mathrm{C}_{11}\right)$ and eluted the $\mathrm{nC}_{132}$ alkane of Polywax 1000 at $180^{\circ} \mathrm{C}$ and 500 bar. On the other hand, Huynh identified $\mathrm{nC}_{136}$ on microcolumns packed with butyl-bonded silica (Kromasil C4) at $150^{\circ} \mathrm{C}$ $170^{\circ} \mathrm{C}$ and 500 bar.

Capillary columns were also successfully used in simdist. The advantages of capillary columns are based on their better deactivation than packed columns, which is a major benefit for reducing aliphatic-aromatic selectivity. Up to now, the heaviest compound identified in capillary SFC was $\mathrm{nC}_{108}$, by Bouigeon et al. [17], at $180^{\circ} \mathrm{C}$ and 500 bar. The stationary phase used was the polydimethylsiloxane, which was found to exhibit lower retention than other tested phases.

As SFC can also elute hydrocarbons starting from $\mathrm{nC}_{20}$ to more than $\mathrm{nC}_{130}$, it is clear that this technique appears as a competitor to HTGC.

Recently, advances in simdist for heavy fractions using capillary SFC has been achieved using a new approach for chromatographic data post-processing. Extended simdist curves have been obtained [18-19]. The aim of this paper is to present an overview on the application of SFC for very high pressure simdist as well as trends for future implementation. Instrumental aspects will be described in detail and result will be compared to GC.

\section{OPERATING CONDITIONS FOR SFC}

\subsection{Choice of Pressure and Temperature}

The supercritical state of the mobile phase is obtained when it is maintained above its critical parameters i.e. above $31.1^{\circ} \mathrm{C}$ and 72.8 bar for pure carbon dioxide. The polarity of the fluid, and hence its solvating power, depends on the pressure and the temperature, which govern the density. Experiments in SFC are usually carried out at constant temperature (fixed above $32^{\circ} \mathrm{C}$ ) while the applied pressure is generally increased during the separation to increase the density. Thus, a supercritical fluid can be considered as a solvent with continuously adjustable solvating power.

\subsubsection{Temperature}

The temperature of the mobile phase is responsible of two antagonist effects: a high temperature decreases the density (reduction of solubility) while the volatility of compounds increases (increase of solubility); it was found that a low temperature (below $100^{\circ} \mathrm{C}$ ) may involve the trapping of the heavy components due to a too low volatility. Temperature has been optimized for the separation of $n$-alkanes mixture (see Sect. 1.5) and $160^{\circ} \mathrm{C}$ appears as the best choice.

\subsubsection{Pressure}

$\mathrm{CO}_{2}$ density is a crucial parameter for SFC separation. In order to elute heavy-molecular weight samples, the $\mathrm{CO}_{2}$ density was gradually increased during the analysis via pressure programming. The injection was performed at an initial pressure of $100 \mathrm{bar}\left(\rho=0.14 \mathrm{~g} / \mathrm{cm}^{3}\right)$. At this pressure, the solvent is very quickly eluted while alkanes higher than $\mathrm{nC}_{24}$ are retained long enough to be separated from the solvent peak. The initial pressure was maintained for $10 \mathrm{~min}$ to allow complete elution of the solvent peak and to minimize the co-elution of light-molecular weight hydrocarbons. The slope of linear pressure gradient was optimized and fixed at $13.3 \mathrm{bar} / \mathrm{min}$ and carried out from 100 to $550 \mathrm{bar}$, which is the maximum operating pressure value the injection valve could stand. The pressure was maintained at 550 bar for $60 \mathrm{~min}$ or more.

\subsection{Instrumentation for SFC}

A general view of SFC experimental system is described in Figure 1: it is constituted by a mobile phase pump, a gas chromatograph, an analytical capillary column, an injector and a detector.

This work was carried out using a gas chromatograph Varian CP-3800 system (Varian, Les Ulis, France) modified for SFC operation. $\mathrm{CO}_{2}$ was pumped using an ISCO 100D syringe pump which can be operated in a pressure ranging from 0.7 to 700 bar and can deliver flows from $0.01 \mu \mathrm{L} / \mathrm{min}$ to $25 \mathrm{~mL} / \mathrm{min}$.

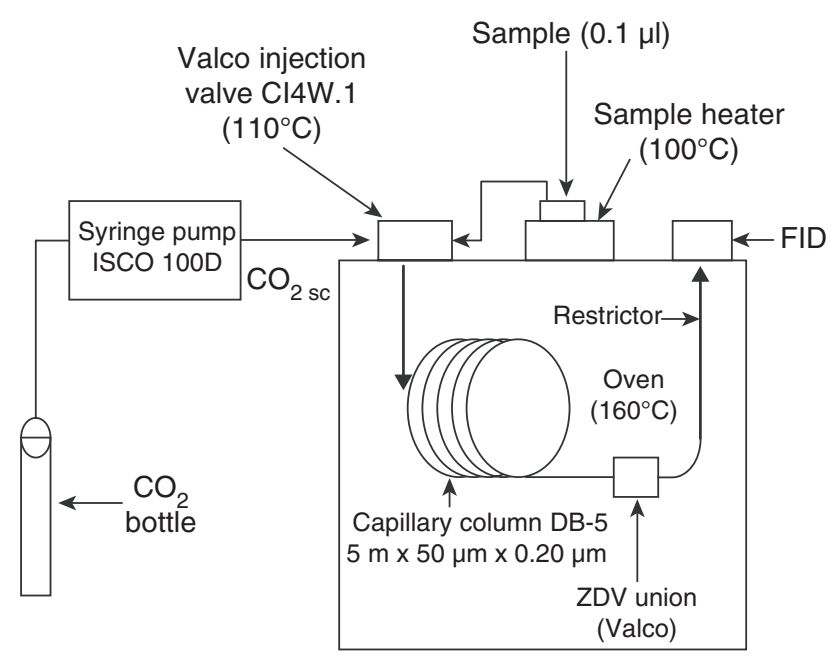

Figure 1

Schematic diagram of the SFC system. 
Injections were made using a Valco CI4W valve (Chromoptic, Courtaboeuf, France) equipped with a specialtype rotor seal having a volume of $0.1 \mu \mathrm{L}$ referenced as SSACWT.1Y. Splitless injection was performed in order to avoid discrimination of the sample. Injection had to be performed at $100^{\circ} \mathrm{C}$ via heating of the valve body which was inserted in a home made ring equipped with heating cartridges controlled by the 3800 GC. Heating of the valve was necessary to dissolve the standards used for correlating retention times and boiling points.

The solutes were dissolved in anhydrous xylene ( $V W R$, France), which has been preferred to carbon disulfide since it can be heated up to $100^{\circ} \mathrm{C}$ to take advantage of better dissolution of the samples.

Flame ionization detector (FID) was used as detector. Temperature of the detector block was set at $350^{\circ} \mathrm{C}$, which is necessary for SFC operation to alleviate for the JouleThompson cooling effect occurring when the $\mathrm{CO}_{2}$ is decompressed. Helium and $\mathrm{H}_{2}$ were purchased from Air Liquide (Nanterre, France) and $\mathrm{CO}_{2}$ was 5.5 quality (Messer, Asnières, France). With regard to the FID, the supercritical fluid had to be depressurized down to atmospheric pressure using an integral restrictor, which was home made from a $50 \mu \mathrm{m}$ I.D. deactivated fused silica capillary tubing from S.G.E. (Villeneuve St Georges, France). The restrictor was connected to column outlet via a zero dead volume Valco union.

\subsection{Analytical Column}

The analytical column needs to be short (5-m length typically), in order to reduce separation time, and of small internal diameter (50- $\mu \mathrm{m}$ typically) to offset the lower diffusion coefficients of supercritical fluids compare to GC conditions. The chosen stationary phase was a $5 \%$ phenyl-polymethylsiloxane phase to ensure the elution of the compounds according to their increasing boiling points. This stationary phase is known to limit retention ship between aromatic and saturate hydrocarbons having the same boiling point in SFC use [17].

In order to favor the elution of heavy compounds, the use of a thin film of stationary phase would seem to be the most judicious option in order to reduce the retention. However, a low film thickness $(0.05 \mu \mathrm{m})$ presents an important disadvantage as the combination between the thin film and the small internal diameter of the columns strongly harms the capacity of the column. As a result, overloading of the column is likely to occur since sample has to be injected into the column without splitting. After various film thicknesses were used to evaluate the influence of this parameter, a film thickness of $0.20 \mu \mathrm{m}$ (phase ratio $\beta=62.5$ ) was chosen as a compromise between column capacity, solute retention and solute focusing during injection [18-19].
Thus 5\% phenyl - 95\% methyl polysiloxane capillary columns (DB-5 $5 \mathrm{~m} \times 50 \mu \mathrm{m} \times 0.20 \mu \mathrm{m}$ Chromoptic, Les Ulis, France) were used for all separations.

It can be seen from the operating conditions elution of high molecular weight compounds in a short time was obtained by working, at the same time, at high temperature and high $\mathrm{CO}_{2}$ density, meaning a high pressure must be reached at the end of the separation. Instrumentation and analytical conditions are summarized in Table 1.

TABLE 1

Operating conditions

\begin{tabular}{l|l}
\hline Parameters & \\
\hline $\begin{array}{l}\text { FID parameters } \\
\text { Temperature } \\
\text { Gas flow-rate }\end{array}$ & $350^{\circ} \mathrm{C}$ \\
& $50 \mathrm{~mL} / \mathrm{min}(\mathrm{He}$ make-up) \\
& $40 \mathrm{~mL} / \mathrm{min}\left(\mathrm{H}_{2}\right)$ \\
& $300 \mathrm{~mL} / \mathrm{min}$ (Air)
\end{tabular}

\subsection{Data Acquisition and Signal Interpretation}

Acquisition of the signal was carried out with Borwin software (JMBS, France) and simdist calculations were performed with Chromdis software (Gecil process, France) using algorithms as defined in ASTM methods.

In order to carry out simdist calculations, the acquisition of 3 chromatograms is necessary: a blank chromatogram using solvent injection (solvent profile), a chromatogram of the mixture of $n$-paraffins (Polywax profile, see Sect. 1.5) and of the chromatogram of the petroleum product to analyze (sample profile). The blank chromatogram is subtracted from the sample chromatogram, and signal integration is performed by slices relating BP and retention time $\left(t_{r}\right)$ according to the acquisition rate $(1.6 \mathrm{~Hz})$. The separation of Polywax is used to obtain the calibration curve.

For some samples whose initial boiling point (IBP) was measured about $150^{\circ} \mathrm{C}$ (effluents of conversion units, see Sect. 1.5), there was a co-elution of the most volatile fraction with the xylene used as solvent. Therefore, the result obtained after blank subtraction is necessary biased. Nevertheless, carbon disulfide can not be used as solvent due to the high temperature required for convenient injection of 
the samples $\left(>100^{\circ} \mathrm{C}\right)$. In order to correct the effect of the solvent, a correction of the simdist curve was performed in the low BP range (typical $150-350^{\circ} \mathrm{C}$ ). The values obtained by the GC simdist were used in this range $\left(150-300^{\circ} \mathrm{C}\right)$ for normalization of the SFC experiment. Only the fist points of the GC simdist curves were used (i.e. 0.5 to $2 \%$ ) (see also Sect. 3.1 and 3.2).

\subsection{Samples}

Calibration mixture: the calibration mixture used to establish the correlation between retention times and BP was prepared by dissolving Polywax 655 and Polywax 1000 (hydrogenated polyethylene wax) in the same ratio in xylene at a concentration of $6.6 \mathrm{~g} / \mathrm{L}$.

A standard mixture of $n$-parrafins including $\mathrm{nC}_{20}, \mathrm{nC}_{30}$, $\mathrm{nC}_{40}, \mathrm{nC}_{50}$ and $\mathrm{nC}_{60}$ in xylene at a concentration of $10^{-3} \mathrm{~mol}$ was also prepared.

Several vacuum residues obtained by straight -run preparative distillation of crude oils have been investigated. They are referred as VR-X where $\mathrm{X}$ is labeled the sample.

The sample VR-1, which was chosen for illustration, has the following properties:

- viscosity $\left(\right.$ at $\left.100^{\circ} \mathrm{C}\right)=3500 \mathrm{cSt}$; density $\left(\right.$ at $\left.15^{\circ} \mathrm{C}\right)=1.045$;

- asphaltenes total content $=21.8 \mathrm{wt} \%$;

- initial boiling point (IBP) as provided by standard simdist $($ ASTM D2887 $)=379^{\circ} \mathrm{C}$;
- eluted fraction at final boiling point as provided by standard simdist (ASTM D2887) $=42 \%$ at $612^{\circ} \mathrm{C}$.

Typical IBP of these compounds were measured higher than $350^{\circ} \mathrm{C}$, involving a complete separation between the solvent tailing peak and the beginning of the chromatographic profile. These crude-oils were purchased by IFP.

Several effluents of conversion units were also studied. They are referred as RS-X where $\mathrm{X}$ is labeled the sample. The sample RS-1, which was chosen for illustration, has the following properties:

- IBP as provided by standard simdist (ASTM D2887) = $154.6^{\circ} \mathrm{C}$;

- asphaltenes total content $=4.2 \mathrm{wt} \%$;

- eluted fraction at final boiling point as provided by standard simdist $\left(\right.$ ASTM D2887) $=80 \%$ at $603.7^{\circ} \mathrm{C}$.

These products were produced by IFP pilot plants.

\section{STANDARD METHOD FOR GC EXPERIMENT}

An IFP standard method was performed to obtain the boiling range distribution of petroleum samples in the range of 100 to $600^{\circ} \mathrm{C}$. This method is derived from the standard method D2887 including the following modifications:

- a specific device was added to the chromatograph to be able to backflush the heaviest part of the sample, which can be considered as having a boiling point above $600^{\circ} \mathrm{C}$;

TABLE 2

Heaviest alkane eluted using capillary SFC

\begin{tabular}{|c|c|c|c|c|}
\hline $\begin{array}{c}\text { Authors } \\
\text { (year) [ref.] }\end{array}$ & $\begin{array}{c}\text { Stationary } \\
\text { phase }\end{array}$ & $\begin{array}{c}\text { Column temperature } \\
\left({ }^{\circ} \mathbf{C}\right)\end{array}$ & $\begin{array}{c}\text { Maximum pressure } \\
(\mathrm{MPa})\end{array}$ & $\begin{array}{c}\text { Heaviest alkane } \\
\text { eluted (BP) }\end{array}$ \\
\hline $\begin{array}{c}\text { Schwartz } \\
(1987)[11]\end{array}$ & $\begin{array}{l}5 \% \text { phenyl- } \\
\text { methylpolysiloxane }\end{array}$ & 100 & 38.5 & $\mathrm{C}_{80}(675)$ \\
\hline $\begin{array}{c}\text { Raynie } \\
(1991)[20] \\
\end{array}$ & $n$-octylpolysiloxane & 150 & 32 & $\mathrm{C}_{100}(719)$ \\
\hline $\begin{array}{c}\text { Shariff } \\
(1994)[16]\end{array}$ & $n$-octylpolysiloxane & NA & NA & $\mathrm{C}_{90}(700)$ \\
\hline $\begin{array}{c}\text { Bouigeon } \\
(1996)[17]\end{array}$ & SB-octyl & 180 & 50 & C96 (712) \\
\hline $\begin{array}{c}\text { Bouigeon } \\
(1996)[17]\end{array}$ & $\begin{array}{l}5 \% \text { phenyl- } \\
\text { methylpolysiloxane }\end{array}$ & 180 & 50 & C92 (704) \\
\hline $\begin{array}{c}\text { Bouigeon } \\
(1996)[17]\end{array}$ & polydimethylsiloxane & 180 & 50 & C108 (732) \\
\hline $\begin{array}{c}\text { Dahan } \\
(2002)[18]\end{array}$ & $\begin{array}{l}5 \% \text { phenyl- } \\
\text { methylpolysiloxane }\end{array}$ & 160 & 55 & $\mathrm{C} 120(750)$ \\
\hline $\begin{array}{c}\text { Dulaurent } \\
(2005)[19]\end{array}$ & $\begin{array}{l}5 \% \text { phenyl- } \\
\text { methylpolysiloxane }\end{array}$ & 160 & 55 & $\begin{array}{c}\mathrm{C}_{126}(759) \\
>\mathrm{C}_{200}\left(>901^{\circ} \mathrm{C}\right)^{*}\end{array}$ \\
\hline
\end{tabular}


- a quantitative procedure is used to be able to establish an accurate distillation curve despite the venting of the heavy part of the sample. It is based on the introduction of internal standard into the sample.

The simdist curve is then normalized taking into account the quantity of product truly eluted at $600^{\circ} \mathrm{C}$. Thus, this method is compatible with heavy ends or samples containing some asphaltenes, leading to true result in the range of $100^{\circ} \mathrm{C}$ to $600^{\circ} \mathrm{C}$ of boiling points.

\section{ELUTION OF N-ALKANES MIXTURE}

\subsection{Last Eluted Alkane}

Thanks to the optimization of operating conditions, the heaviest eluted $n$-paraffin was $\mathrm{nC}_{126}$, which appears as quite higher than previously reported as it is shown in the Table 2, indicating a significant extension of the calibration range. An example of chromatogram obtained by the separation of calibration mixture by SFC is given on the Figure 2, including an enhanced view of the last part of the chromatogram. The superposition of the blank and of the calibration mixture chromatogram shows that the elution of $n$-alkanes is continuing well beyond the last identified alkane $\left(\mathrm{nC}_{126}\right)$; unfortunately no standard compounds have been identified.

The determination of $\mathrm{nC}_{120}\left(750^{\circ} \mathrm{C}\right)$ was observed routinely, which means a benefit of 20 carbons with regard to high temperature GC (e.g. end-point benefit of $50^{\circ} \mathrm{C}$ ).

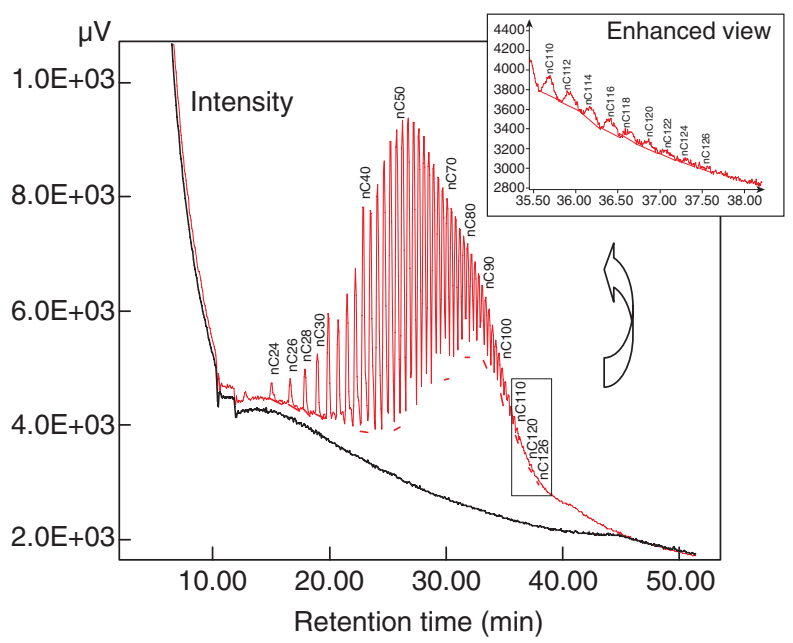

Figure 2

Chromatogram of the calibration mixture (Polywax 655 and 1000). The caption shows an enhanced view of the last part of chromatogram. The solvent chromatographic profile is overlaid.

Operating conditions: see Table 1.
The stability of the stationary phase, which is known as critical for Simdist, was daily checked by the injection of a standard mixture of $n$-paraffins. 20 injections of this test mixture over 35 days lead to retention time standard deviation lower than $0.3 \%$.

\subsection{Modeling of Alkane Retention}

Owing to the lack of resolution, it was not possible to identify elution peaks at the end of the chromatogram of calibration mixture, as shown in Figure 2. In order to estimate the retention time of heavier $n$-alkanes, a study aiming at modeling the elution of the $n$-alkanes was carried out. The extension of the calibration curve was then considered.

Indeed, since the pressure gradient covering the 100550 bar domain is linear, all the alkanes are eluted according to the same chromatographic mechanism during SFC experiment. So if a model was able to describe the elution of the first 120 alkanes, it would then be possible to extrapolate it over the whole pressure gradient. The same approach can not be usually used for high temperature GC due to:

- the variation of eluting condition at the end of experiment;

- to the degradation of compounds at the highest oven temperature required for eluting the heavy fraction.

A model establishing a relationship between the retention time (RT) and the number of the carbon atom (NC) has been established by the use of experimental retention times in the range of $\mathrm{nC}_{50}$ to $\mathrm{nC}_{100}$. The discussion on the choice of the mathematical relation and the physical interpretation of this model in term of elution mechanism is reported elsewhere [19].

Under conditions reported in Table 1, the retention time $\mathrm{RT}$ is bound to the number of carbon $\mathrm{NC}$ according to Equation (1):

$$
\mathrm{RT}=a+b \ln (\mathrm{NC})
$$

where $a$ and $b$ are constant bound to the stationary phase. $a$ and $b$ have been calculated each 10 injections via the analysis of a Polywax standard.

This logarithmic model has been evaluated in the range of $\mathrm{nC}_{100}$ to $\mathrm{nC}_{118}$ : the experimental $\mathrm{RT}$ of $n$-alkanes were known and these values have been compared to predicted RT. The comparison between predicted and measured RT for these identified alkanes over $\mathrm{nC}_{100}$ has lead to a bias lower than $0.5 \%$ rel. For illustration purpose, Figure 3 represents the relationship between RT and carbon number for alkanes including observed $\mathrm{RT}$ (from $\mathrm{nC}_{26}$ to $\mathrm{nC}_{118}$ ) and predicted or calculated RT (from $\mathrm{nC}_{100}$ to $\mathrm{nC}_{162}$ ). In this case, the end of the elution profile for the calibration mixture (polywax) was corresponding to alkane $\mathrm{nC}_{162}$ according to the model (or $c a$. $805^{\circ} \mathrm{C}$ ). The predictive power of the model for the calculation of RT of the $n$-alkanes having more than 100 carbon atoms has been evaluated from statistical point of view using 30 day analysis. 


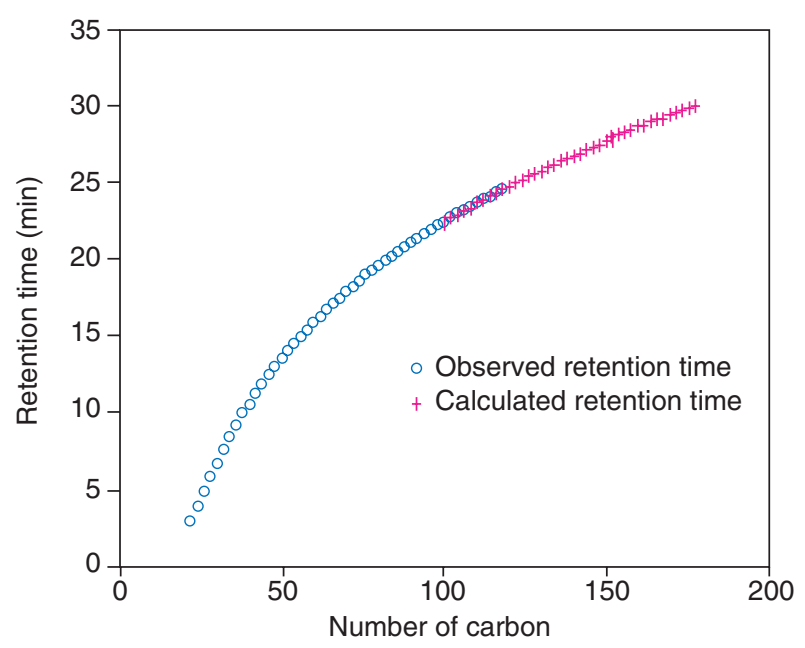

Figure 3

Retention times in function of carbon atom numbers for alkanes from calibration mixture (Polywax) using calculated and observed retention times.

Operating conditions: see Table 1.

However, when real petroleum samples have been injected, a fraction of the effluent has been eluted after the retention time corresponding to $\mathrm{nC}_{162}$ and before the end of the gradient. It has been decided to carry out the calibration between the end of the elution of the Polywax mixture up to the end of the elution of the petroleum sample, as far as the elution occurs during the pressure gradient (same elution mode).

In that case, the last $n$-alkane eluted at the end of the pressure gradient was estimated as being $\mathrm{nC}_{200 \pm 2}\left(\mathrm{ca} .900^{\circ} \mathrm{C}\right)$, which means an increase of about 100 carbons is obtained compared to the standard high temperature GC method.

The use of model up to $\mathrm{nC}_{162}$ was called "SFC simdist", because it was base on the elution of a calibration mixture whereas the use of the model up to $\mathrm{nC}_{202}$ was called "extended SFC simdist", up to $900^{\circ} \mathrm{C}$.

\subsection{Conversion of Retention Time into AEBP}

Boiling points (BP) of $n$-alkanes is tabulated until 69 carbons. From $\mathrm{nC}_{69}$ up to $\mathrm{nC}_{100}$, $\mathrm{BP}$ are generally those defined by American Petroleum Institute using a linear regression. Several works have reported the calculation of BP for heavier compounds [5]. For this work, a logarithmic correlation has been performed for the determination of AEBP for the heavy $n$-alkanes, as previously reported by Huynh et al. [15].

The elution of $\mathrm{nC}_{200}$ means a benefit of 100 carbons with regard to high temperature $\mathrm{GC}$ or an end-point benefit of $140^{\circ} \mathrm{C}$.

\section{APPLICATIONS OF EXTENDED SFC SIMDIST TO HEAVY CONVERSION PRODUCTS}

\subsection{Qualitative Analysis of Residues and Heavy Products}

Extended SFC simdist was carried out to characterize a vacuum residue (VR-1) and a full range heavy conversion product from a conversion unit (RS-1), both being representative of this type of products.
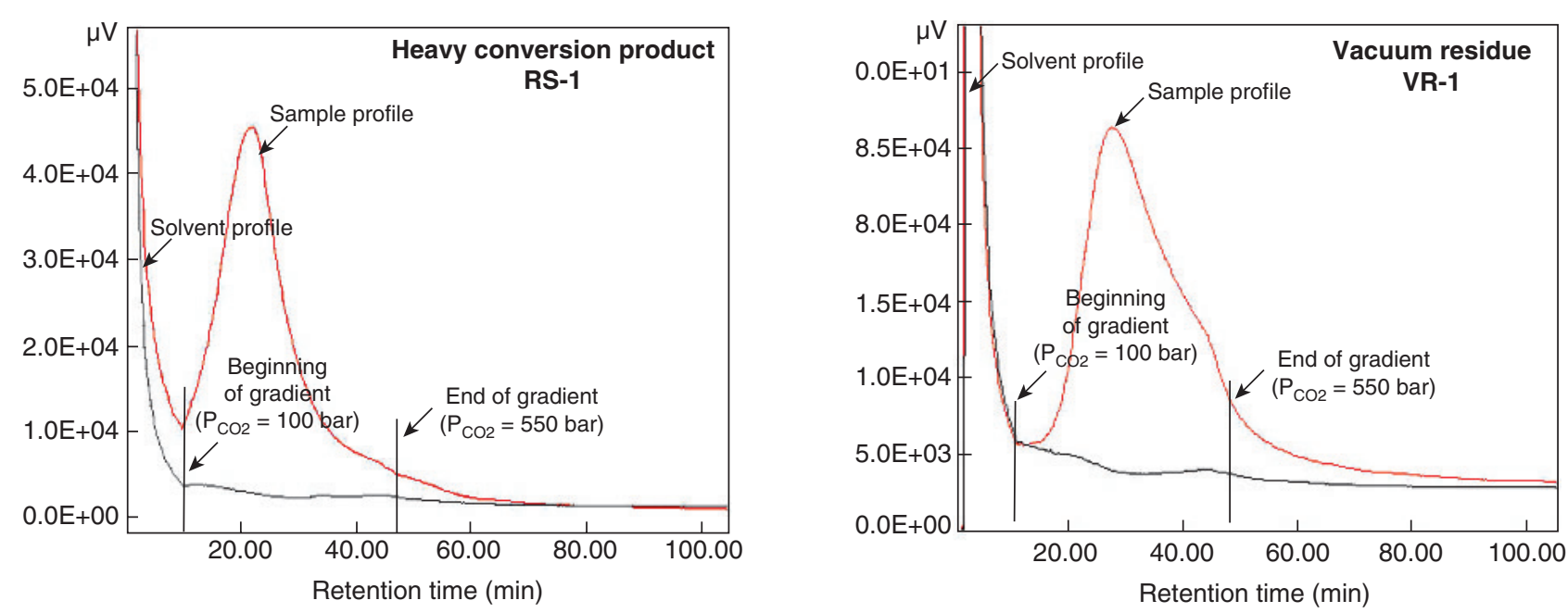

Figure 4

Chromatograms obtained by SFC for vacuum residue of crude oil (VR-1) and heavy conversion product (RS-1). The solvent chromatographic profile is overlaid.

Operating conditions: see Table 1. 
Figure 4 shows the chromatograms obtained using SFC for each sample. The chromatographic profile obtained for blank injection (solvent profile) has been overlapped to the chromatogram from each sample (sample profile). The beginning and the end of the pressure programming operation were also indicated in the Figure 4.

For the RS-1 sample (full range heavy product), it is clear that:

- The lightest compounds were co-eluted with the solvent elution peak owing to the back tailing of the solvent peak.

- A return to the baseline of the FID response was currently observed at the end of the experiment but it occurs rather after the elution of the last fraction of Polywax mixture.

For the VR-1 sample (vacuum residue), it can be observed that:

- The solvent elution peak was well separated from the beginning of the elution of the sample.

- No return to the baseline was observed at the end of the experiment. So, a part of the sample has not been eluted after $60 \mathrm{~min}$ at 550 bar.

\subsection{Quantitative Procedure}

\subsubsection{Normalization of SFC Raw Data for a Full Range Heavy Conversion Products}

For RS-X samples, co-elution of the most volatile components with the xylene has been observed in the range of low boiling points $\left(\mathrm{ca} .150\right.$ to $\left.350^{\circ} \mathrm{C}\right)$. This fact involves a higher IBP by SFC simdist compared to IBP obtained by GC simdist. Thus, for these samples, a normalization of the SFC results was carried out using the results obtained by GC simdist: the eluted \% obtained initially for IBP by SFC simdist has been replaced by the value obtained by GC simdist for the same boiling point. Then, the entire SFC simdist curve had to be normalized according to the new IBP value. This procedure has been systematically used for heavy product, whose IBP was currently below $200^{\circ} \mathrm{C}$.

\subsubsection{Comparison between GC and SFC for Heavy Conversion Products}

Figure 5 shows the simulated distillation curves obtained for the heavy conversion product RS-1 using:

- GC simdist;

- SFC simdist without the correction of IBP;

- Extended SFC Simdist including with the correction of IBP and the extension of the calibration range up to the end of the gradient of pressure.

This comparison demonstrates the interest of the normalization of SFC simdist curve to correct IBP values as an excellent agreement is observed after normalization between $\mathrm{GC}$ simdist and extended SFC simdist in the range 346 to $604^{\circ} \mathrm{C}$.

This means that extended SFC simdist is well calibrated and appears as quantitative since the same quantity of sample

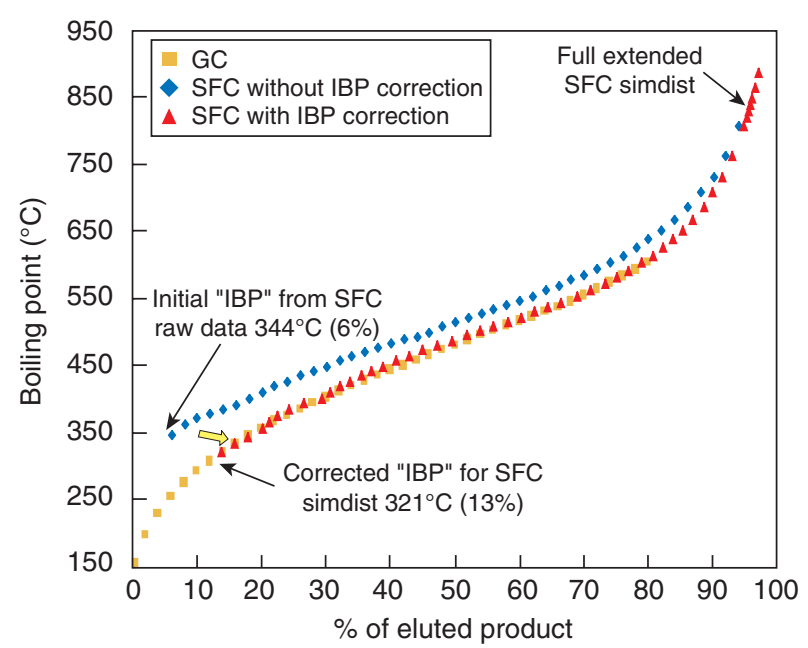

Figure 5

Comparison of simulated distillation curves using simulated distillation curves obtained for heavy conversion product RS1 using GC simdist, SFC simdist without IBP correction and extended SFC simdist with IBP correction and full extension of calibration curve.

Operating conditions: see Table 1.

is corresponding to the same range of boiling point. Moreover, SFC manages to provide an extension of the simulated distillation curve. This extended SFC simdist has been calibrated until the end of the pressure gradient, which corresponded to $\mathrm{nC}_{203} n$-alkane or $886^{\circ} \mathrm{C}$ as boiling point according to the retention model previous discussed. This means that $96.9 \%$ of the sample has been eluted at the end of the pressure gradient. The remaining $3.1 \%$ are corresponding to the compounds eluting after the end of the pressure gradient and for which no calibration can be used.

It is worth indicating that:

- The RS- 1 sample contains $4.1 \mathrm{wt} \%$ of asphaltenes: despite the signal is returning to the baseline at the end of chromatogram, it can not be deduced they are eluted from the column. Work is on progress to answer this difficult question as no standard compound can be used for checking their elution.

- This approach is an important improvement of the characterization of the sample since only $80 \mathrm{wt} \%$ of this sample was eluted at $604^{\circ} \mathrm{C}$, which is the end of calibration using GC method for simdist.

- The fact that the GC and extended SFC distillation curves are in agreement in the range of 346 to $604^{\circ} \mathrm{C}$ is very encouraging.

Table 3 reports the results obtained for other heavy conversion products. This table indicates:

- The true IBP, which has been obtained by the standard GC simdist method; 
TABLE 3

Results for various full range heavy conversion products

\begin{tabular}{|c|c|c|c|c|c|c|}
\hline \multirow[b]{2}{*}{ Samples } & \multicolumn{3}{|c|}{ GC } & \multicolumn{3}{|c|}{ SFC } \\
\hline & $\begin{array}{l}\text { true IBP } \\
\left({ }^{\circ} \mathrm{C}\right)\end{array}$ & $\begin{array}{c}\mathrm{FBP}^{(3)} \\
\left({ }^{\circ} \mathrm{C}\right)\end{array}$ & $\begin{array}{c}\% \text { of calibrated } \\
\text { fraction }^{(2)}\end{array}$ & $\begin{array}{l}r a w \text { IBP } \\
\left({ }^{\circ} \mathrm{C}\right)^{(1)}\end{array}$ & $\begin{array}{l}\mathrm{FBP}^{(3)} \\
\left({ }^{\circ} \mathrm{C}\right)\end{array}$ & $\begin{array}{c}\% \text { of calibrated } \\
\text { fraction }^{(2)}\end{array}$ \\
\hline RS-1 & 154.5 & 603.7 & 80 & 347.4 & 872 & 96 \\
\hline $\mathrm{RS}-2$ & 162 & 614.1 & 78 & 352.2 & 864.7 & 94 \\
\hline RS -3 & 163.9 & 614.7 & 78 & 349.9 & 898.2 & 90 \\
\hline RS -4 & 156.1 & 605.9 & 78 & 347.3 & 888.8 & 92 \\
\hline RS -6 & 322.4 & 611.4 & 90 & 350.9 & 863.9 & 99 \\
\hline RS -7 & 316.6 & 614 & 88 & 354.6 & 901.4 & 94 \\
\hline RS -8 & 331.2 & 610.3 & 91 & 348.6 & 859.2 & 99 \\
\hline RS -9 & 260.4 & 611 & 88 & 349.3 & 840.5 & 99 \\
\hline RS -10 & 175.8 & 613.3 & 67 & 348.5 & 900 & 94 \\
\hline
\end{tabular}

(1)Raw IBP as provided by SFC experiments without normalization.

(2)Fraction that was eluted at the end of the gradient (SFC) or at the backflusch time (GC). Only this fraction is used for the determination of simulated distillation curve.

(3)FBP means the boiling point at the end of the calibration curve. This is the final boiling point of the distillation curve.

- The FBP, which has been obtained by the standard GC simdist method, and the weight percent of eluted fraction corresponding at this FBP;

- The raw "IBP", which is obtained without any correction of the effect of the solvent;

- The FBP, which is obtained by extended SFC simdist, and the weight percent of eluted fraction corresponding at this FBP.

For that example, the average difference the calculated boiling point by each method (extended SFC or GC simdist) at the same eluted fraction (x \%) has been evaluated as lower than $6^{\circ} \mathrm{C}$, as already reported.

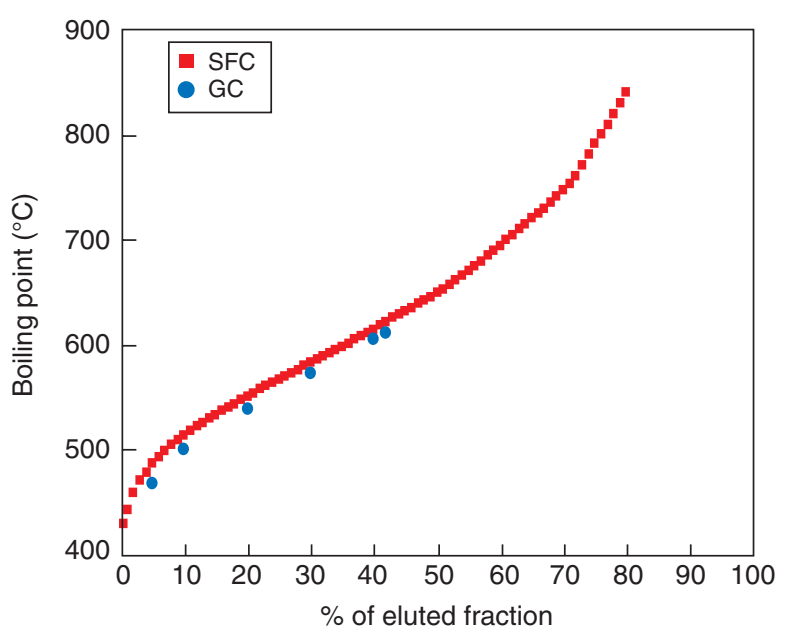

Figure 6

Comparison of simulated distillation curves using simulated distillation curves obtained for vacuum residue VR-1 using GC simdist and extended SFC simdist.

Operating conditions: see Table 1.

\subsubsection{Comparison between GC and SFC for Vacuum Residues of Crude Oils}

Figure 6 shows the simulated distillation curves obtained vacuum residue VR-1 using GC and extended SFC simdist. For this kind of sample, the correction of IBP is not necessary owing to the high initial boiling point. A good agreement is observed between GC and extended SFC simdist in the range of 430 to $605^{\circ} \mathrm{C}$. However, a bias is observed at the beginning of the SFC simdist curve.

As expected, SFC is able to provide an extended simulation curve, which has been calibrated up to the end of the pressure gradient.

According to the results obtained for SFC, $82 \%$ of the product has been eluted at the end of the pressure gradient. This is corresponding to the elution of $\mathrm{nC}_{196}$ (boiling point of $853^{\circ} \mathrm{C}$ ), according to the retention model previous discussed.

The GC standard method was only able to elute $42 \%$ of the entire sample corresponding to a $\mathrm{FBP}$ of $605^{\circ} \mathrm{C}$.

Again, it is interested to notice that:

- The VR-1 sample contains $15.3 \%$ of asphaltenes and $35.3 \%$ of resins. Undoubtedly, these heavy compounds are partially eluted by SFC and it must be pointed out that no plugging of the system occurred during the experiments.

- This approach demonstrates an important improvement of the characterization of this type of samples has been accomplished since only $42 \%$ of this sample were eluted at $605^{\circ} \mathrm{C}$ in $\mathrm{GC}$ !

\section{CONCLUSIONS}

The ability of SFC to provide the elution of heavy ends has been demonstrated for the analysis of heavy conversion products and for vacuum residues of crude oils. Indeed, the chromatographic profiles, which were obtained using SFC 
under high temperature and very high pressure, show a continuous elution of compounds, far beyond the end of the elution of $n$-parrafins provided by the injection of Polywax 1000 standard mixture. The use of dedicated models for calculating AEBP for heavy alkanes and for determining the correlation between retention time sand carbon numbers allow the extension of the calibration curve, until the end of the pressure gradient. Thus, a way to calibrate the SFC chromatogram has been introduced leading to simulated distillation curve up to $\mathrm{nC}_{200}$ or $\mathrm{ca} .850^{\circ} \mathrm{C}$ as equivalent boiling point.

The application of this approach for heavy conversion products has shown an excellent agreement between extended SFC data and GC data, demonstrating the highest interest of this approach for a better understanding of conversion processes. The study of vacuum residues shows more complex results. Nevertheless, it seems to be possible to elute a part of heavy fractions of full range petroleum cuts like resins or asphaltenes.

Therefore, the extension of the simulated distillation curve by the use of SFC data enables undoubtedly a better display of the nature of the samples.

Besides, work is on progress to take benefit from detection facilities of SFC, which allows direct hyphenation to specific detectors working at gaseous phases, to carry out the detection of specific elements, such as sulfur or nitrogen. Thus, Simdist curves of sulfur compounds or nitrogen compounds should be possible, which is an important need for feedstocks characterization.

\section{ACKNOWLEDGEMENTS}

Dr. Th. Gauthier, Dr. A. Quignard and Dr. I. Guibard are deeply acknowledged for fruitful discussions and for providing the samples.

\section{REFERENCES}

1 Sie S.T., Rjinders G.W.A. (1967) Chromatography with supercritical fluids. Anal. Chim. Acta., 38, 31.

2 Peaden P.A. (1994) Simulated distillation of petroleum and its products by gas and supercritical fluid chromatography - a review. J. High Res. Chromatog., 17, 203-211.

3 Workman D.S., Noel F., Watt M.R. (1993) Simulated distillation of petroleum fractions by capillary gas-chromatography. J. Chromatogr. Sci., 31, 96.

4 Durand J.P., Bré, A., Béboulène, J.-J., Ducrozet, A., Carbonneaux, S. (1998) Simulated distillation methods for petroleum fractions with minimal residue in the boiling range of $35-700^{\circ}$ C. J. Chromatogr. Sci., 36, 9, 431-434.
5 Thomson J.S., Rynaski A.F. (1992) Simulated distillation of wax samples using supercritical fluid and high temperature gas chromatography. J. High Res. Chromatog., 15, 227-234.

6 ASTM D 3710 (1990) Boiling Range Distribution of Gasoline and Gasoline Fractions by Gas Chromatography, American Society for Testing and Materials.

7 ASTM D 2887 (1993) Boiling Range Distribution of Petroleum Fraction by Gas Chromatography, American Society for Testing and Materials.

8 ASTM D 5307 (1992) Determination of Boiling Range Distribution of Crude Petroleum by Gas Chromatography, American Society for Testing and Materials.

9 Petroff N., Hoscheitt A., Durand J.P. (1987) Automated simulated distillation by gas chromatography: Performance test for petroleum product control. J. Chromatogr., 395, 241.

10 ASTM D 6352 (2004) Standard Test Method for Boiling Range Distribution of Petroleum Distillates in Boiling Range from 174 to $700^{\circ} \mathrm{C}$ by Gas Chromatography, American Society for Testing and Materials.

11 Schwartz M., Brownlee H.E., Boduszynski, R.G., Su F. (1987) Simulated distillation of high-boiling petroleum fractions by capillary supercritical fluid chromatography and vacuum thermal gravimetric analysis. Anal. Chem., 59, 1393.

12 Roberts I. (1995) Supercritical-fluid chromatography, in Chromatography in the Petroleum Industry, Adlard, E.R. (Ed.), Elsevier, NL, chap. 11.

13 Robert E. (1999) in Supercritical fluid chromatography and extraction, Caude M., Thiebaut D. (Eds.), Harwood Academic Publishers, Amsterdam, chap. 9.

14 Sotty Ph., Rocca J.L., Grand C. (1993) 15th Int. Symp. on Capillary Chromatography, Riva del Garda.

15 Huynh V.K., Thiébaut D., Caude M., Robert E. (2006) submitted.

16 Shariff S.M., Tong D., Bartle, K.D. (1994) Simulated distillation by supercritical fluid chromatography on packed columns. J. Chromatogr. Sci., 32, 541-546.

17 Bouigeon Ch., Thiébaut D., Caude M. (1996) Long packed column supercritical fluid chromatography: Influence of pressure drop on apparent efficiency. Anal. Chem., 68, 3622-3630.

18 Dahan L., Thiebaut D., Bertoncini F., Espinat D., Quignard A. (2004) Simulated distillation of heavy fraction by capillary supercritical fluid chromatography : evaluation and comparison with gas chromatography Prepr. Pap.-Am. Chem. Soc., Div. Fuel Chem. 49, 18 .

19 Dulaurent A., Dahan L., Thiebaut D., Bertoncini F., Espinat D. (2006) Evaluation of a predictive retention model for high temperature cimulated distillation of heavy fraction by capillary supercritical fluid chromatography, submitted to J. Chromatogr. A.

20 Raynie D.E., Markides K.E., Lee M.L., (1991) Boiling range distribution of petroleum and coal-derived heavy ends by supercritical fluid chromatography. J. Microcolumn Sep., 3, 423.

Final manuscript received in February 2006 work owned by others than IFP must be honored. Abstracting with credit is permitted. To copy otherwise, to republish, to post on servers, or to redistribute to lists, requires prior specific permission and/or a fee: Request permission from Documentation, Institut français du pétrole, fax. +33147527078 , or revueogst@ifp.fr. 